\title{
Reconsidering Convergence Culture and Its Consequences for Literary Studies
}

\author{
Claudia Georgi
}

\section{Introduction}

As the wide range of contributions to the present volume illustrates, 'convergence culture' is a phenomenon that applies to various areas of contemporary culture. It covers developments in academic disciplines as diverse as literary, cultural, and media studies, digital humanities, translation studies, art history, musicology, and even ecology. While its general applicability may confirm Henry Jenkins's appraisal of convergence culture as forming a general "paradigm shift" (2006, 243), it may also expose it as a new buzzword that is so vague that it can serve any academic discipline in describing any context.

After a brief investigation of Jenkins's definition of 'convergence culture' and his related notions of 'participatory culture' and 'transmedia storytelling,' three main questions will be considered in the following in order to shed light on the benefits and limitations of his approach. Firstly, does 'convergence culture' describe new phenomena or did they already exist long before the term was coined? Secondly, is 'transmedia storytelling' a useful concept that extends beyond the limits of established terms such as 'adaptation,' 'medial transposition,' or 'transmediality'? And thirdly, what are the consequences of Jenkins's observations for the humanities and specifically for literary studies? 


\section{Convergence Culture}

In his research and publications on convergence culture, Jenkins combines the more distanced approach of an academic ${ }^{1}$ with the insider experience of an active member of various fan communities $(2006,12 ; 1992,4-5)$. He has further tried to bridge the gap between various perspectives via his long-time involvement in communicating research in media and communication studies to the media industry and educational institutions $(2006,12-13)$.

Especially in his earlier publications such as Textual Poachers: Television Fans and Participatory Culture (1992) Jenkins admits that his observations with regard to fan communities and their intense engagement with media may not apply to society in general. As he observes, "[f]an culture differs in a qualitative way from the cultural experience of media consumption for the bulk of the population. [...] The fan audience is in no sense representative of the audience at large" (Jenkins 1992, 286). In this sense, these early publications explicitly question the general validity of Jenkins's findings and assert that he has not "drawn upon fandom as a means of developing a new theory of media consumption" (Jenkins 1992, 286). It is only in his more recent publications that Jenkins has broadened his perspective to consider also more average users and consumers of new media in order to develop in full his theory of 'convergence culture.' This is especially true of Convergence Culture: Where Old and New Media Collide (2006) and of his most recent volume Spreadable Media: Creating Value and Meaning in a Networked Culture (2013), the latter coauthored with Sam Ford and Joshua Green. As opposed to Jenkins's earlier and more tentative remarks, these studies claim that 'convergence culture' is no marginal phenomenon restricted to fan communities but represents a general "paradigm shift" (2006, 243).

But what exactly are these changes or shifts he labels as 'convergence culture'? According to Jenkins, convergence culture can be described as

the flow of content across multiple media platforms, the cooperation between multiple media industries, and the migratory behavior of media audiences who will go almost anywhere in search of the kinds of entertainment experiences they want. Convergence is a word that manages to describe technological, industrial, cultural, and social changes depending on who's speaking and what they think they are talking about. [...] I will argue here against the idea that convergence should be understood primarily as a technological process bringing together multiple media functions within the same devices. [...] Convergence does not occur through media

\footnotetext{
1 Henry Jenkins is the Provost Professor of Communication, Journalism, Cinematic Arts, and Education at the University of Southern California and used to be director of the Comparative Media Studies graduate degree programme and Peter de Florez Professor of Humanities at the Massachusetts Institute of Technology ("Henry Jenkins" 2014).
} 
appliances, however sophisticated they may become. Convergence occurs within the brains of individual consumers and through their social interactions with others. (2006, 2-3)

As this quotation explicitly states, convergence culture is not simply determined by the availability of new media appliances and the advance of digitization. Although such technological innovations are prerequisites for media convergence, they do not constitute an imperative for convergence culture, nor do they suffice to explain it (Jenkins 2006, 11; Jenkins, Ford, and Green 2013, 3). Instead, convergence culture figures as a far-reaching and holistic phenomenon that is influenced by a combination of technological, economic, social, cultural, and global conditions (Jenkins 2001, 93).

José van Dijck shares Jenkins's objection to technological determinism and his awareness of other factors when he identifies a 'culture of connectivity' defined as "a sociotechnical ensemble" (van Dijck 2013, 14), an "online ecosystem [that] is embedded in a larger sociocultural and political-economic context where it is inevitably molded by historical circumstances" (9). Some critics, however, simply equate convergence with the mere technological fusion of media via digitization. Hence Anders Fagerjord proclaims:

$[\ldots]$ convergence is over. The media have already converged. [...] Convergence as a development must logically end at some point either because media cease to converge, or because all media have converged into one, or have reached a limit where further convergence is impossible. $(2010,188$ 189; emphasis in the original)

Instead of such reduction of convergence to the merging of technological and specifically digital devices or to the substitution of established media by new hypermedia, Jenkins conceives of convergence as a cooperation and cross-fertilization in which "old and new media collide" $(2006,2)$. He further elaborates that "[i]f the digital revolution paradigm presumed that new media would displace old media, the emerging convergence paradigm assumes that old and new media will interact in ever more complex ways" (2006, 6; see also 2008, 274, 290). This chimes with Jay David Bolter and Richard Grusin's accounts of such medial interaction rather than substitution, an interdependence they describe as a reciprocal process of 'remediation' involving both old and new media. Based on a wealth of examples, they argue convincingly that "[w] hat is new about new media comes from the particular ways in which they refashion older media and the ways in which older media refashion themselves to answer the challenges of new media" (Bolter and Grusin 1999, 15). For Jenkins, too, convergence is a development that affects, but does not replace, established media and that will not end with the invention of a single medium to encompass all other media. Convergence, therefore, "refers to a process, not an endpoint" (Jenkins 2006, 16). What is as important for this process 
as the technological conditions of media convergence is the social and cultural potential of convergence culture and the way it affects the mutual relations between media, the media industry, producers, and consumers.

\section{Participatory Culture}

With a view to capturing these social and cultural implications of convergence culture, Jenkins further introduces the idea of a 'participatory culture.' It entails a new perception of consumers (readers, viewers, users, etc.) as active participants in cultural production and reception. With this idea, Jenkins builds on Alvin Toffler's notion of the 'prosumer' as a particularly active consumer who is "increasingly being drawn into the production process" (Toffler 1980, 290) so that "conventional distinctions between producer and consumer vanish" (292). Moreover, Jenkins also seizes on Axel Bruns's related concept of 'produsage' that applies specifically to the context of social software and Web 2.0 (Bruns 2008, 5) where "users are always already necessarily also producers of the shared knowledge base, regardless of whether they are aware of this role - they have become a new, hybrid, produser" (2; emphasis in the original). Based on these notions, Jenkins similarly highlights the active role of consumers who often figure as (co-)producers at the same time. With specific reference to fan communities, he observes that "fandom does not preserve a radical separation between readers and writers. Fans do not simply consume preproduced stories; they manufacture their own fanzine stories and novels, art prints, songs, videos, performances, etc." (Jenkins 1992, 45). A brief consideration of collective encyclopaedias such as the Wikipedia or social media platforms such as YouTube with their user-generated content, however, illustrates that even beyond fan communities a single individual can simultaneously act as both consumer and producer. In their interaction with media content, today's consumers thus assume and smoothly shift between the roles of 'translators,' 'multipliers,' 'appraisers,' 'lead users,' 'retro curators,' 'pop cosmopolitans,' etc., to name but a few of the functions assigned to them by Jenkins, Ford, and Green $(2013,297)$.

In addition to the consumers' increased participation in the production of media content, Jenkins furthermore identifies a trend towards communal reception in temporary knowledge communities and an increased relevance of collective intelligence $(2006,26,54,245)$, a development he describes as a "shift from individualized and personalized media consumption toward consumption as a networked practice" (244). According to Jenkins, the formation of such networks has a democratic potential $(2006,247)$. At the same time, he also cautions that such democratization is no automatic result of the technological advances associated with convergence and participatory culture but needs to be actively fought for $(2008,293-$ 294). Although convergence culture theoretically allows everyone to participate and facilitates free expression, the 'digital divide' and the 'participation gap' in access to technology and media literacy impede equal use of communication networks 
across and within cultures (Jenkins 2006, 23; 2010b). When speaking of convergence and participatory culture, it is therefore important to bear in mind that these are relative rather than absolute terms (Jenkins, Ford, and Green 2013, 193) to describe a more or less global but not (yet) universal dissemination. Jenkins, Ford, and Green highlight the limits of participation when stating that "not everyone is allowed to participate, not everyone is able to participate, not everyone wants to participate, and not everyone who participates does so on equal terms" (2013, 298). On the other hand, those who have the means to participate often also feel compelled to make use of these for fear of being excluded from social interaction otherwise. This aspect becomes perceptible in José van Dijck's description of the peer pressure of being part of online sociality, which makes it seem as if "[o]pting out of connective media [wa]s hardly an option" (van Dijck 2013, 174). Yet, as S. Elizabeth Bird correctly points out, opportunities for participation in convergence culture are not limited to "online produsage" $(2011,509)$ based on digital technology but can also be sought in "offline audience activity" (506) so that being able to participate in convergence culture does not solely depend on having access to the internet.

\section{Transmedia Storytelling}

Whichever form active participation takes, the increased engagement of consumers is the prerequisite and guiding principle for what Jenkins calls the "new aesthetic" of transmedia storytelling that results from media convergence (2006, 20-21). As Jenkins defines it,

[a] transmedia story unfolds across multiple media platforms, with each new text making a distinctive and valuable contribution to the whole. In the ideal form of transmedia storytelling, each medium does what it does best [...]. Each franchise entry needs to be self-contained so you don't need to have seen the film to enjoy the game, and vice versa. Any given product is a point of entry into the franchise as a whole. (2006, 95-96)

Using The Matrix franchise as a prime example of transmedia storytelling, Jenkins illustrates how the consumers can access a storyworld via diverse media channels or "touch points" $(2006,63)$ such as films, comics, games, websites, etc. By gathering various pieces of information and putting them together like a puzzle, the consumers therefore actively (re)construct the storyworld. Yet, as Marie-Laure Ryan and Jan-Noël Thon remark, they do not need to construct this fictional world from scratch each time but can instantly immerse themselves in a world that already is at least partly familiar to them from related versions that have been circulated via other media channels (Ryan and Thon 2014, 1). 
Rather than providing redundant information, each version ideally offers additional perspectives in order to allow for a more intense experience of the storyworld so that " $[\mathrm{t}]$ he whole is worth more than the sum of the parts" (Jenkins 2006, 102). Yet, the pieces of information that are scattered across distinct media do not always add up to a coherent and unified storyworld but may sometimes present alternative or even contradictory versions of a fictional universe (Jenkins 2009). In keeping with Jenkins, Marie-Laure Ryan therefore observes that " $[\mathrm{t}]$ he various elements of a transmedial system can either expand a storyworld through processes that respect previous content or create logically distinct, though imaginatively related, storyworlds through modifications and transpositions that alter existing content" (Ryan 2014, 42). This difference between coherent and divergent versions of transmedia storyworlds often primarily depends on how strictly a transmedia franchise is controlled by the media industry and how well it is protected from unauthorized extensions or alterations. Whenever fan contributions are encouraged, in other words, this may lead to alternative and sometimes, though not necessarily, contradictory versions of a storyworld. Jenkins himself endorses "a logic of multiplicity" that tolerates alternative versions and values their contribution to a storyworld, irrespective of whether these versions have been authorized or not (Jenkins 2009). On the whole, he not only observes an increased acceptance of transmedia storytelling as a new narrative mode, but he even discerns a rising "transmedia expectation" among the consumers who often take it for granted that narratives spread across distinct media (Jenkins 2009).

From the point of view of the media industry, transmedia storytelling has clear economic motives of finding ever new ways of promoting and expanding a brand across various media as a transmedia franchise (Jenkins 2006, 104). Beyond its narrative function, transmedia storytelling can thus also be seen as an effective marketing strategy. The consumers, on the other hand, are motivated by the desire to fill gaps in the narrative, to immerse themselves more completely in the storyworld, or even to enhance it themselves. Additionally, the mere market and peer pressure on consumers to support certain brands should not be underestimated either. As Mélanie Burdaa concludes, two diametrically opposed processes are at work in transmedia storytelling: while the producers disperse the information across multiple media channels, the consumers reassemble it and piece it back together $(2013,212)$. Depending on whether we take the perspective of the media industry or the consumers, transmedia storytelling thus actually shifts between divergence and convergence.

In addition to increased consumer commitment, transmedia storytelling demands a certain type of narratives that are 'spreadable.' " $[1] \mathrm{f}$ it doesn't spread, it's dead" is the simple formula Jenkins, Ford, and Green use to summarize this requirement $(2013,1)$. In other words, content needs to offer various "access points" for the recipients and to be presented in "easy-to-share formats" (6). Spreadability, however, does not necessarily imply a broad distribution of content. Instead, it 
may also refer to the possibility for smaller groups of recipients to engage more deeply with this content (22), a phenomenon Jenkins also calls "drillability" in keeping with media scholar Jason Mittell’s terminology (Jenkins 2009).

\section{Precursors of Convergence Culture}

Are convergence culture, participatory culture, and transmedia storytelling really new phenomena or are they related to earlier developments? Jenkins, Ford, and Green actually relativize the alleged degree of novelty when affirming that "[p]articipatory culture is not new - it has, in fact, multiple histories [...] which go back at least to the nineteenth century" (2013, 297). I would even argue that at least in some media the intention of blurring producers and consumers via participation is much older than this. Theatre, for instance, has always lent itself to audience participation due to its simultaneity of production and reception which allows the audience to witness and engage with the mise-en-scène and to give direct feedback. This may occur in the form of applause and booing or via more elaborate strategies of participation as in interactive performances where the spectators themselves are asked to perform.

Jenkins, Ford, and Green mention examples from narrative fiction and more specifically refer to $19^{\text {th }}$-century serialized novels by authors like Charles Dickens who, while still in the process of writing, could react to the readers' responses concerning the already published instalments and could adjust the narratives to their suggestions. The serialized format thus required the readers' active engagement in putting together the pieces of the narrative from the individual instalments (Jenkins, Ford, and Green 2013, 133-134), while also offering them a certain degree of participation in designing the plot development.

The $19^{\text {th }}$ century also witnessed further precursors of participatory culture and transmedia storytelling such as the development of the Newgate novels that were published - often also in serialized form - in England between the late 1820s and the 1840s. Newgate novels such as Edward Bulwer-Lytton's Paul Clifford (1830) or William Harrison Ainsworth's Jack Sheppard (1839-1840) were closely related to their cultural, social, legal, literary, and material contexts and engaged their readers in various ways. These novels exploited and also fuelled a general fascination with violence but, more importantly, they also served as literary responses to legal reforms of capital punishment in the first half of the 19th century (Hollingsworth $1963,27)$. They fused distinct literary genres by drawing inspiration from newspaper articles that related actual crimes, from published confessions of criminals, and most of all from the Newgate Calendars, a collection of criminal biographies (Hollingsworth 1963, 5-6). That the public interest in crimes and punishment was not exclusively a literary phenomenon can further be seen in the promotion of related merchandise in other media such as mementos and portraits of criminals or souvenirs such as hangman's ropes (Hollingsworth 1963, 8). In this sense, the New- 
gate novels established an early form of transmedia franchise. By making reference to public debates and actual crimes as access points into their storyworlds, the Newgate novels moreover blurred fictional renderings and actual crimes and in this way allowed the readers more deeply to immerse themselves in the storyworlds by relating to their own realm of experience.

Karen Swallow Prior considers the storm of enthusiasm that followed the publication of Samuel Richardson's Pamela (1740) as an even earlier example of transmedia storytelling because the novel was quickly taken up in parodies or sequels and spread across media in the form of paintings, prints, etc. Moreover, Richardson acknowledged active readership by modifying the novel according to reader feedback in its second edition (Swallow Prior 2013). Going even further back in time, stories from the Bible and figures from ancient Greek mythology can be seen as yet earlier precursors of transmedia storytelling since they could and can still be encountered in distinct media such as oral stories or sermons, written texts, tapestries, paintings, etc. (Jenkins 2006, 119-120; Ryan and Thon 2014, 3).

Although these examples may not count as participatory culture and transmedia storytelling in a strict sense, they demonstrate that convergence culture has its forerunners and did not suddenly appear out of thin air in the past decades. When looking at contemporary examples by comparison, it becomes clear nonetheless that there is a difference in kind and extent between such earlier forms and current convergence culture because the possibilities of transmedia storytelling and consumer participation have become more elaborate and extensive. As Jenkins, Ford, and Green observe, "what happened in a predigital world now occurs with exponentially greater speed and scope" $(2013,12)$. One reason for this can be found in the invention of new technologies. They make stories available across a wider range of new media and platforms that are easily accessible and, specifically in the case of Web 2.0, encourage interactive use.

Yet, as mentioned above, the technological progress goes hand in hand with changed cultural, social, economic, and aesthetic practices and expectations. In this sense, a shift can be observed for example in the role of consumers. Their own contributions and reactions are no longer only seen as unsolicited feedback of secondary importance, but are explicitly encouraged and acknowledged by the media industry as integral parts of creative processes that directly shape media content and form. Such changes have gradually led to the emergence of new participatory practices such as 'crowdsourcing,' 'crowdfunding,' and 'crowdsurfing' (Jenkins, Ford, and Green 2013, 246-254) or the sharing of knowledge in collaborative online encyclopaedias such as the Wikipedia (Jenkins 2006, 254). What is more, they have also contributed to the formation of new transmedia subgenres with their own aesthetics such as blogs and vlogs, Twitter poetry, spoetry, filk music, vids, eBooks, or e-mail novels, to name but a few examples. Depending on one's perspective, the convergence of media and the collaboration or synergies of those engaged in them could thus also be seen as a divergence or diversification of audiences, practices, and genres. 
I would argue, however, that behind the technological innovations, the modified cultural and social practices of participation, and the creation of hitherto unknown transmedia genres and aesthetics lies a basic human need that has merely found a new form or degree of expression: convergence culture caters to the basic desire of bridging the gap between fiction and reality by approximating art and everyday experience. It complies with the wish to immerse oneself in fictional worlds, to gain access to parallel realities, to explore and hold on to them, and to shape them from the inside. It is this need that already in the $18^{\text {th }}$ and $19^{\text {th }}$ centuries made recipients want to influence the further development of stories, to voice approval and disagreement with them, or to appropriate storyworlds via the acquisition of related memorabilia; and it is the same desire that now vents itself in star cult and makes consumers want to share their ideas with other consumers on internet platforms, to leave their imprint on media products via fan activities, or to interact with fictional characters on Twitter or Facebook.

\section{Terminological Considerations}

If 'participatory culture' and 'transmedia storytelling' have their precursors and are the expression of a timeless desire to hold on to storyworlds or to shape them from within, is it really necessary to introduce these terms and to proclaim a new 'convergence culture' or could the described phenomena not simply be covered by broadening the scope of existing terms such as 'adaptation,' 'medial transposition,' or 'transmediality'? Eckart Voigts and Pascal Nicklas pose the question of whether transmedia storytelling is simply "the currently dominant mode of adaptation and appropriation" (Voigts and Nicklas 2013, 140). Without committing themselves to a definite answer, they suggest that participatory culture at least changes the established workings of adaptation as we have known them (140).

Linda Hutcheon's "Preface to the First Edition" of $A$ Theory of Adaptation conveys the impression that participatory culture and transmedia storytelling push the boundaries of her framework of adaptation when she observes that "[a]daptation has run amok" (Hutcheon 2013, xiii). In her "Preface to the Second Edition" she asks where to draw the line between an adaptation and an "on-going, unstable, open-ended 'multitext"' and demands that theories of adaptation be expanded to cover not only adaptations of a story but also adaptations of entire 'story worlds' or literary 'heterocosms' (Hutcheon 2013, xxiv). Siobhan O'Flynn's epilogue to Hutcheon's book shares this uncertainty with regard to the limits of adaptation and transmedia storytelling when detecting "more overlaps and blurrings than distinctions" between the two and identifying "many projects that resist easy categorization" (O'Flynn 2013, 187). The main difference Hutcheon herself perceives between previous adaptations and the current mode of transmedia storytelling concerns their respective relevance in the sense that transmedia storytelling has 
become "the new entertainment norm, not the exception" (Hutcheon 2013, xxiii), an observation that ties in with Jenkins's assumption of an increasing "transmedia expectation" (Jenkins 2009).

Occasionally, the difference between adaptation and transmedia storytelling is formulated in terms of the respective degree of novelty and ingenuity of distinct versions of a story. As mentioned above, in transmedia storytelling each version should ideally be self-contained, provide a new entry into the storyworld, and make a "distinctive and valuable contribution to the whole" (Jenkins 2006, 95-96). To stick to the previous example, all of the transmedial versions of The Matrix provide equally valid yet novel entries into its storyworld and only offer a complete picture when they are pieced together (Jenkins 2006, 101-102). This induces Jenkins to propose a distinction "between adaptation, which reproduces the original narrative with minimum changes into a new medium and is essentially redundant to the original work, and extension, which expands our understanding of the original by introducing new elements into the fiction" (Jenkins 2009). Accordingly, Jenkins considers recent forms of transmedia storytelling to be more integrated, interrelated, and complex than adaptations $(2004,40)$. Mélanie Burdaa agrees with this assessment in her own judgment that "transmedia storytelling is richer than crossmedia adaptations since it develops a whole universe instead of only adapting the same storylines to different platforms" (2013, 205). Unfortunately, such verdicts are not uncommon and O'Flynn therefore deplores that "[a]daptation is (still) positioned consistently as a lesser, more simplistic mode of reworking content" (O'Flynn 2013, 195-196). Such denigration of basic adaptations as being more redundant than instances of transmedia storytelling, however, cannot be upheld given the many cases of adaptations that do not merely transpose identical content into a different medium but themselves offer new approaches, interpretations, and contexts. Even Jenkins has to admit that adaptations often also provide new insights into or interpretations of known stories (Jenkins 2009).

The proposition of the Producers Guild of America to distinguish between adaptations and transmedia storytelling according to the number of involved storylines, media, or platforms proves equally unreliable. As the Guild formulates, a "Transmedia Narrative project or franchise must consist of three (or more) narrative storylines existing within the same fictional universe" (qtd. in Jenkins 2010a). This would imply, however, that what is categorized as an adaptation as long as only two media are involved, would suddenly have to be considered as transmedia storytelling the moment a further adaptation brings a third medium into play.

What could possibly also be seen as a new aspect of transmedia storytelling in comparison to conventional adaptations is the degree to which the respective reworkings of stories are authorized by their original creators. In this context, it could be assumed that the various versions of transmedia storyworlds are developed or at least authorized by the initial authors or producers themselves, whereas adaptations are unauthorized, subsequent reworkings by persons other than the original creators. Applying Werner Wolfs criteria for the "genesis of intermediali- 
ty" to medial transposition or transmedial contexts, one could thus try to draw a line between the "primary," i.e. initial and authorized conception of transmedia storyworlds, and the "secondary," i.e. retroactive and unauthorized reworking of stories in the form of adaptations (Wolf 1999, 39). Although this may be a general tendency, the boundaries between both options are fluid when it comes to individual cases. On the one hand, many authors have adapted their own works into other media without thinking of them as forming related transmedia storyworlds as in the case of Dante Gabriel Rossetti's paintings of The Blessed Damozel as visual renderings of his eponymous poem (first published in 1850) or Noël Coward's screenplay for the Brief Encounter film (1945) based on his own play Still Life (1936). On the other hand, what is initially considered as an unauthorized or unsolicited transposition into another medium may eventually be accepted as an official part of a transmedia storyworld as in the case of Trevor Truran's board game "Thud" that was inspired by Terry Pratchett's Discworld novels and in turn lent its name to one of Pratchett's sequels. In the end, which transpositions are officially accepted by the producers owning the copyrights has little to do with their status as adaptation or transmedia storytelling. It is less a question of authorial intent or authorization than of expectations of economic profit, the wish to control or prohibit unsolicited transpositions, or the desire to increase interest or brand loyalty by demonstratively encouraging fan production and transpositions.

Rather than focussing on questions of authorization in order to distinguish between adaptation and transmedia storytelling, it is more fruitful to consider how transmedia storytelling changes attitudes of reception with regard to related notions of 'originality.' Although Hutcheon stresses that adaptations are not necessarily derivative or secondary to an 'original,' she complains that they are often perceived as inferior works and judged according to conservative demands of fidelity to their original (2013, xiv-xv). As opposed to this, transmedia storytelling questions the primacy and authority of the original and treats different versions of a story as equally valid. According to Hutcheon, "[i]t obviously becomes harder and harder to think in terms of 'original' or 'source' stories or even story worlds when dealing with these kinds of adaptations, because here simultaneity, not priority, reigns" (2013, xxiv).

It is reasonable to assume that the difference between originals and their reworkings becomes less relevant and that the notions of 'source' or 'hypotext' and 'target' or 'hypertext' are rendered dispensable in transmedia storytelling where content spreads across media in a way that often makes it impossible to identify an original. Jenkins accordingly considers transmedia storytelling as far more than a transformation of one medium into another and proclaims "a move from mediumspecific content toward content that flows across multiple media channels" (2006, 243). Many storyworlds are conceived, designed, and marketed as being transmedial from the very beginning. This is true, for instance, of The Matrix, a project consisting of movies, animated short films (The Animatrix in 2003), a series of comics, and computer games (Jenkins 2006, 101). Where an original source can still be 
identified, as in the case of Star Wars, its transmedia storyworld is often expanded in a process that is collective and participatory in that it explicitly encourages audience contributions as equally valid parts of the storyworld. The official Star Wars fan film contests that are organized on an annual basis serve as only one of many possible examples of such procedures (Jenkins 2006, 131). Whereas adaptation is a case of 'medial transposition' that transforms an original work or aspects of it into another medium (Rajewsky 2005, 51), transmedia storytelling thus comes closer to 'transmediality' where elements related to content or form occur in distinct media without necessarily having a traceable origin in any of them (Rajewsky 2005, 46).

In addition to the decreased importance of the 'original,' transmedia storytelling also levels cultural hierarchies expressed by labels such as 'high' versus 'low' or 'popular' culture because it does not give priority to any medium at the expense of another medium. A novel, film, video game, or vlog, for example, may thus all be equally accepted as valid contributions to a transmedia storyworld. This obviously renders the notion of a universally valid literary canon even more problematic than it has already been so far.

The reduced relevance of originality that makes it possible for fan contributions to figure as equally accepted versions of a transmedia storyworld leads us back once more to the new role of the consumer. Participatory culture implies modes of participation that can no longer be easily controlled by the media industry. It describes multi-directional processes where the roles of producers and consumers, authors and readers can no longer strictly be kept apart and where consumers creatively appropriate stories in forms that may in turn be seized upon and re-appropriated by the media industry (Jenkins 2006, 148). This new appreciation of the creative activity of consumers is not explicitly taken into account by theories of adaptation or medial transposition. With its two main pillars of 'transmedia storytelling' and 'participatory culture,' convergence culture thus implies two new aspects: the downgrading of the original and the upgrading of the prosumer. It is these two aspects that may, after all, justify the proclamation of a new 'convergence culture' for phenomena that in other respects do not differ so much from well-established concepts.

Ultimately, coining new terms is less relevant than understanding the changing conditions of cultural production and reception as such. Furthermore, the choice of terminology will always depend on the respective research focus. For an interdisciplinary approach that takes into consideration aesthetic, cultural, social, and technological aspects, 'convergence culture' will therefore be a more useful concept. Yet, for tracing how specific themes and aesthetic or formal aspects travel across media, the frameworks of intermediality and transmediality may be the better tools. Although many of the described phenomena are of global importance, their analysis moreover occurs in different academic contexts so that the notion of 'convergence culture' seems to have a stronger 'fan base' among American scholars, whereas theories of inter- and transmediality are better established in Europe- 
an academic discourse. Rather than substituting one theory by the other and considering them as mutually exclusive, it would thus be more productive to exploit their potential for comparisons and cross-fertilizations.

\section{Consequences for Literary Studies}

Irrespective of the choice of terminology and theoretical frameworks, it cannot be denied that the past decades have seen the emergence of new conditions and practices of literary production, distribution, and reception. Sooner or later, these changes will inevitably affect the focus of teaching and research in the humanities and will call for more interdisciplinary and collaborative approaches that will combine literary, media, and cultural studies with technological, sociological, and other investigations. For literary scholars this also means looking beyond medial boundaries and building on their expertise in literary criticism without hierarchically placing literary versions of storyworlds above their extensions in other media.

What is more, convergence culture will also leave an imprint on core concepts of literary studies such as authorship, readership, originality, or genre conventions. First of all, the increasingly participatory modes of production, distribution, and reception as well as the blurring of the roles of producers and consumers challenge established ideas of authorship and readership since readers may suddenly become authors or co-authors and hence enter into a dialogue with the texts. In this sense, reception turns into a more active and creatively responsive process. Moreover, especially in the context of fandom, acts of reading and interpreting also become increasingly social and interactive (Jenkins 1992, 45, 278). Eckart Voigts therefore calls for a "new reception studies [that] will need to overcome the self-enclosure of merely thinking about audiences as consumers and start to fully grasp the fact that audiences are themselves producers, publishers and distributors of texts" (Voigts 2013 , 154). Nonetheless, collective readership and active 'prosumption' should not be overestimated either because many readers still opt for more traditional offline reading experiences.

Concomitant with the new modes of production, distribution, and reception, a new aesthetic understanding of cultural artefacts and literary works is called for that no longer considers them as fixed products complete in themselves. Instead, they are now to be seen as interrelated and collaborative projects that are always in process and never finished. Such works in progress invite the recipients to participate in their production from the outset, to create or choose between concurrent versions, and to formulate their individual interpretations and reactions to them. As mentioned above, this poses a challenge to the binary perception of 'original' versus 'reworking.' It also questions the distinction between 'high' and 'low' culture and undermines the authority of the canon by placing originals and reworkings, canonical and popular texts on the same level (Jenkins 1992,17). What is more, the idea of unfinished works in progress even subverts the idea of authorial intention 
as a binding, authoritative touchstone of reception. As Jenkins adds for consideration, participatory culture moreover promotes "an understanding of intellectual property as "shareware"' $(2006,256)$ so that it will be necessary in the long run to reconsider copyright laws and redefine what constitutes fair use, plagiarism, and piracy (189-190).

We do not need to see into the future in order to discern that the new modes of production and reception, of authorship and readership also go hand in hand with the formation of new transmedial subgenres and corresponding genre conventions. No matter whether these hybrid subgenres are timeless or short-lived, whether they have stable or shifting characteristics, they demand flexible and versatile genre definitions able to accommodate new formats and they require new reading skills and enhanced media literacy. At the same time, it is also essential to examine the effects such new genres have on the popularity of those established formats that refuse consumer participation or expansion across media. As transmedia storytelling transcends media and genre boundaries, Jenkins observes an "emergence of new story structures, which create complexity by expanding the range of narrative possibility rather than pursuing a single path with a beginning, middle, and end" (2006, 119). To account for this increasing complexity of narrative structures will thus pose a new challenge to narratology.

\section{Conclusion}

Although media convergence, participatory culture, and transmedia storytelling upset cultural hierarchies and modify established notions of authorship, readership, or originality, they are not entirely new phenomena. Media convergence entails the continued existence of and interaction with old media; participatory culture builds on established practices of cultural production, distribution, and reception; and transmedia storytelling has not replaced known genres but blends them across media in order to attain new narrative complexity. Individually, these aspects could also be covered by established concepts such as 'remediation,' 'digitization,' 'prosumption,' 'adaptation,' 'medial transposition,' or 'transmediality.' Convergence culture, however, claims to go beyond the boundaries of any of these individual categories by considering their combined effects and their mutual reinforcement and by straddling technological, aesthetic, social, and cultural dimensions. Jenkins aims high with this extended scope and it is yet to be decided whether his concept can deliver what it promises. Whether we agree with his proclamation of a new 'convergence culture' or not, we cannot deny the benefits of his approach in general if only because it raises the awareness of cultural changes and encourages the humanities to accept the challenges they pose. If we do not simply abandon tried concepts and, as Jenkins counsels, do not indulge in either utopian or dystopian discourses (Jenkins 2014, 273), the concept of 'convergence culture' may indeed help us deal with new cultural developments. 
Let me close with Henry Jenkins, Sam Ford, and Joshua Green's slightly ominous proclamation that we live at "a moment of transition, one in which an old system is shattering without us yet knowing what is going to replace it, one which is ripe in contradictions" $(2013,295)$. The present volume is meant to be an attempt at building something new out of the alleged ruins of the old system without eschewing these contradictions.

\section{Works Cited}

Bird, S. Elizabeth. "Are We All Produsers Now? Convergence and Media Audience Practices." Cultural Studies (special issue: Rethinking Convergencel Culture) 25.4-5 (2011): 502-516.

Bolter, Jay David, and Richard Grusin. Remediation: Understanding New Media. Cambridge, MA and London, UK: MIT, 1999.

Bruns, Axel. Blogs, Wikipedia, Second Life, and Beyond: From Production to Produsage. New York: Peter Lang, 2008.

Burdaa, Mélanie. "Following the Pattern': The Creation of an Encyclopaedic Universe with Transmedia Storytelling." Adaptation (issue: Adaptation, Transmedia Storytelling and Participatory Culture) 6.2 (2013): 202-214. Web. 18 December 2014.

Fagerjord, Anders. "After Convergence: YouTube and Remix Culture." International Handbook of Internet Research. Ed. Jeremy Hunsinger, Lisbeth Klastrup, and Matthew Allen. Dordrecht and Heidelberg: Springer, 2010. 187-200.

"Henry Jenkins." USC Annenberg School for Communication and Journalism. USC University of Southern California. 2014. Web. 18 December 2014.

Hollingsworth, Keith. The Newgate Novel 1830-1847: Bulwer, Ainsworth, Dickens, and Thackeray. Detroit: Wayne State UP, 1963.

Hutcheon, Linda, with epilogue by Siobhan O'Flynn. A Theory of Adaptation. 2006. $2^{\text {nd }}$ ed. London and New York: Routledge, 2013.

Jenkins, Henry. Textual Poachers: Television Fans and Participatory Culture. New York and London: Routledge, 1992.

---. "Convergence? I Diverge." Technology Review 104.5 (2001): 93. Web. 18 December 2014.

---. "The Cultural Logic of Media Convergence." International Journal of Cultural Studies 7.1 (2004): 33-43. Web. 18 December 2014.

---. Convergence Culture: Where Old and New Media Collide. New York and London: New York UP, 2006. 
---. "Afterword: Reflections on Politics in the Age of YouTube." Convergence Culture: Where Old and New Media Collide. 2006. Henry Jenkins. Updated with new afterword. New York and London: New York UP, 2008. 271-294.

---. "The Revenge of the Origami Unicorn: Seven Principles of Transmedia Storytelling (Well, Two Actually. Five More on Friday)." Confessions of an AcaFan: The Official Weblog of Henry Jenkins. 12 December 2009. Web. 18 December 2014.

--. "Hollywood Goes "Transmedia." Confessions of an Aca-Fan: The Official Weblog of Henry Jenkins. 27 April 2010a. Web. 18 December 2014.

---. "Towards a New Civic Ecology: Addressing the Grand Challenges." Confessions of an Aca-Fan: The Official Weblog of Henry Jenkins. 15 October 2010b. Web. 18 December 2014.

---. "Rethinking 'Rethinking Convergence/Culture." Cultural Studies 28.2 (2014): 267-297.

Jenkins, Henry, Sam Ford, and Joshua Green. Spreadable Media: Creating Value and Meaning in a Networked Culture. New York and London: New York UP, 2013.

O'Flynn, Siobhan. Epilogue. A Theory of Adaptation. Linda Hutcheon. $2^{\text {nd }}$ ed. London and New York: Routledge, 2013. 179-206.

Rajewsky, Irina O. "Intermediality, Intertextuality, and Remediation: A Literary Perspective on Intermediality." Intermédialités 6 (2005): 43-64. Web. 18 Dec. 2014.

Ryan, Marie-Laure. "Story/Worlds/Media: Tuning the Instruments of a MediaConscious Narratology." Storyworlds across Media: Toward a Media-Conscious Narratology. Ed. Marie-Laure Ryan and Jan-Noël Thon. Lincoln and London: U of Nebraska P, 2014. 25-49.

Ryan, Marie-Laure, and Jan-Noël Thon. "Storyworlds across Media: Introduction." Storyworlds across Media: Toward a Media-Conscious Narratology. Ed. Marie-Laure Ryan and Jan-Noël Thon. Lincoln and London: U of Nebraska P, 2014. 1-21.

Swallow Prior, Karen. "The New, Old Way to Tell Stories: With Input from the Audience." The Atlantic. 18 October 2013. Web. 18 December 2014.

Toffler, Alvin. The Third Wave. New York: William Morrow, 1980.

van Dijck, José. The Culture of Connectivity: A Critical History of Social Media. Oxford and New York: Oxford UP, 2013.

Voigts, Eckart. "The Performative Self: Reception and Appropriation under the Conditions of 'Spreadable Media' in 'Bastard Culture."' Anglistik: International Journal of English Studies 24.2 (2013): 151-168. 
Voigts, Eckart, and Pascal Nicklas. "Introduction: Adaptation, Transmedia Storytelling and Participatory Culture." Adaptation (issue: Adaptation, Transmedia Storytelling and Participatory Culture) 6.2 (2013): 139-142. Web. 18 December 2014.

Wolf, Werner. The Musicalization of Fiction: A Study in the Theory and History of Intermediality. Amsterdam and Atlanta, GA: Rodopi, 1999. 